\title{
A GIS-BIM Approach for the Evaluation of Urban Transformations. A Methodological Proposal
}

\author{
M. GRIMALDI*, C. GIORDANO, G. GRAZIUSO, S. BARBA, I. FASOLINO \\ Department of Civil Engineering, University of Salerno, via Giovanni Paolo II 132, 84084, \\ Fisciano, SA, ITALY
}

\begin{abstract}
The implementation and monitoring of the urban transformations provided by the planning tools require a control by the responsible territorial authorities on the compliance of the proposed transformations with the technical and binding rules of the current plans. Considering the complexity of the urban and territorial scale, professionals need a tool capable of satisfying the planning, design and management needs of urban space. The large amount of data and the possibilities of managing the multiple information contained in a BIM model can, indeed, be integrated usefully and declined at higher scales than the single building one, since they can be extended from the sphere of pure architectural design to planning sector. In such a wide context, the GIS-BIM approach can represent a real shift of paradigm aimed at managing the complexity of urban processes more effectively.
\end{abstract}

Key-Words: - Urban Plan, GIS, BIM, urban indicators, urban transformations evaluation.

Received: June 17, 2021. Revised: November 18, 2021. Accepted: December 20, 2021. Published: January 17, 2022.

\section{Introduction}

Planning actions can be defined as the result of all anthropic processes that produce a physical transformation of cities. These actions have different impacts, depending on the urban transformation they define. It is possible to distinguish actions that create new objects, actions that can modify existing objects and actions that aim to remove completely objects [1]. The effects that the combination of these actions determine are very complex, considering also the spatial component of the objects affected by the transformation.

The formalization of the relationships between the effects and the actions become essential to support the decision maker in selecting a suitable set of actions and contributing to an efficient urban transformation [2]. To achieve this goal, it is necessary to build a system for assessing the impact of these actions based on the simulation of the urban transformation, which can be defined according to the urban indicators that the Urban Plan provides. The simulation of the application of the threshold values attributed by the Urban Plan to each indicator results in the $n$ design configurations that the specific area can assume. It is, therefore, necessary to build a model of knowledge of the territory that combines transformations on the urban scale and on the building scale dynamically. The aim of tying together the different components of knowledge of a territory, inside and outside the built environment, is similar to look carefully at both the ways of representing them and the tools to govern them. This means to be equipped with a syncretic vision to reconcile aspects apparently very distant in time, space and nature [3]. The knowledge of a territory, indeed, can be defined with its representation and performed in various ways, i.e. using different formal modelling techniques and parametric data representations [4].

Currently, the representative models of digital cities are based on geospatial data deriving from a Geographic Information System (GIS), that can be considered an indispensable tool for the development of the territory and, in general, for spatial governance [5]. Certainly, it marks an evolution in the world of urban planning but planning often requires data that GIS alone cannot provide.

Conversely, Building Information Modelling (BIM) can support the detailed semantics of parts of buildings or other functional parts of the city [6]. Indeed, a 3D model created in a BIM environment is based on a smart representation of the object that allows a systematic association of data, attributes and parameters [7-12]. The model, intended as a complete and centralized information repository, can be used during the entire life cycle of a building and data from such a model can be updated and shared promptly [13]. 
Each discipline involved in the knowledge of a territory has its own scope and, therefore, focuses differently on the things that are modelled and on the way in which they are modelled $[14,15]$. However, the interoperability, i.e. the ability of a system to exchange data and information with other systems or programs, opens an interesting connection between the urban and the building scale [16]. The data coming from a GIS environment and those deriving from a BIM model, indeed, can be integrated with the consequent advantage of managing the planning information in a coordinated manner $[17,18]$. Thus, it is possible to move from the simple concepts of GIS and BIM to the one of City Information Modelling (CIM) that is characterized by a multidisciplinary union of all the spatial data of the model [19]. In addition, the CIM can involve a multiplicity of actors in order to collaborate in the development of sustainable, participatory and competitive cities [20].

Starting from these considerations, in this paper a methodology of integration of GIS and BIM is described and applied to a case study in the municipality of Nocera Inferiore (South Italy) in order to design new dynamic spatial scenarios of the urban transformations, with a real time control on both the urban and the building scale.

\section{Methodology}

In order to create a parametric model useful in the urban planning phase, a methodology that allows the association of the classic urban indicators with BIM system was defined. This parametric model, integrated with the data coming from a GIS system, allows the creation of a database able to facilitate the stakeholders in the management of information and in the evaluation of the urban transformation processes.

The methodology can be divided into three phases (figure 1), i.e.:

1. GIS environment modelling;

2. BIM environment modelling;

3. Scenarios construction and assessment of urban transformations.

Each phase is organized in several steps. While the first two phases are related to the urban and the buildings contexts respectively, the third phase contribute to define the model for the generation of different scenarios.

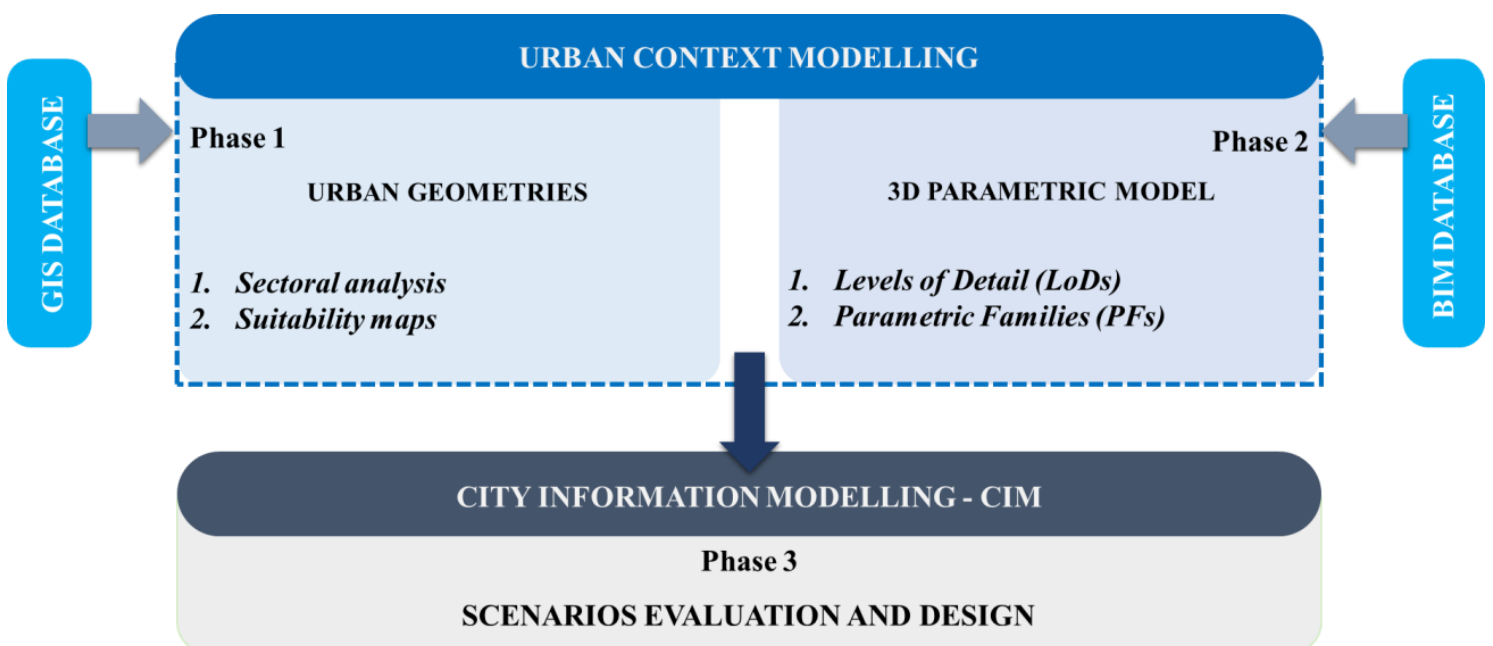

Fig. 1: Methodology for the CIM definition and the construction of dynamic scenarios.

The first phase, which is implemented in GIS environment, can be divided into two steps. The first step concerns the acquisition and systematization of all the information deriving from the planning system of the study area, from the cognitive layers about the use of the soil, the morphology and geology of the soil. The second step involves the synthesis with overlay map operations of the information layers and the construction of suitability maps of the transformation in terms of distribution of the lots and their appropriate urban functions.
The second phase can be, also, divided into two steps and includes the definition of levels of detail (LoD), for step 1, and definition of parametric families (PFs), with regards to step 2. In the BIM environment, the geometric representation of the construction elements can vary in granularity, depending on the design state, with the definition of several LoDs, such as the symbolic (LoD A), generic (LoD B), defined (LoD C), detailed (LoD D), specific (LoD E), performed (LoD F) and updated (LoD G) ones (figure 2). To support the 
dynamic nature of the design process, step 2 of the second phase is connected with the generative modelling approach of BIM, which allows the changes of object models quickly and efficiently by creating parametric families. For example, the thickness of a wall component can be simply changed by adjusting the only width parameter, while the change of geometry is implicit [21]. The parametric model, that is the output of the second phase, allows the modelling of objects intended as datasets, interchangeable through the Industry Foundation Classes (IFC) data model, i.e. the international BIM standard for interoperability with more chance of success.

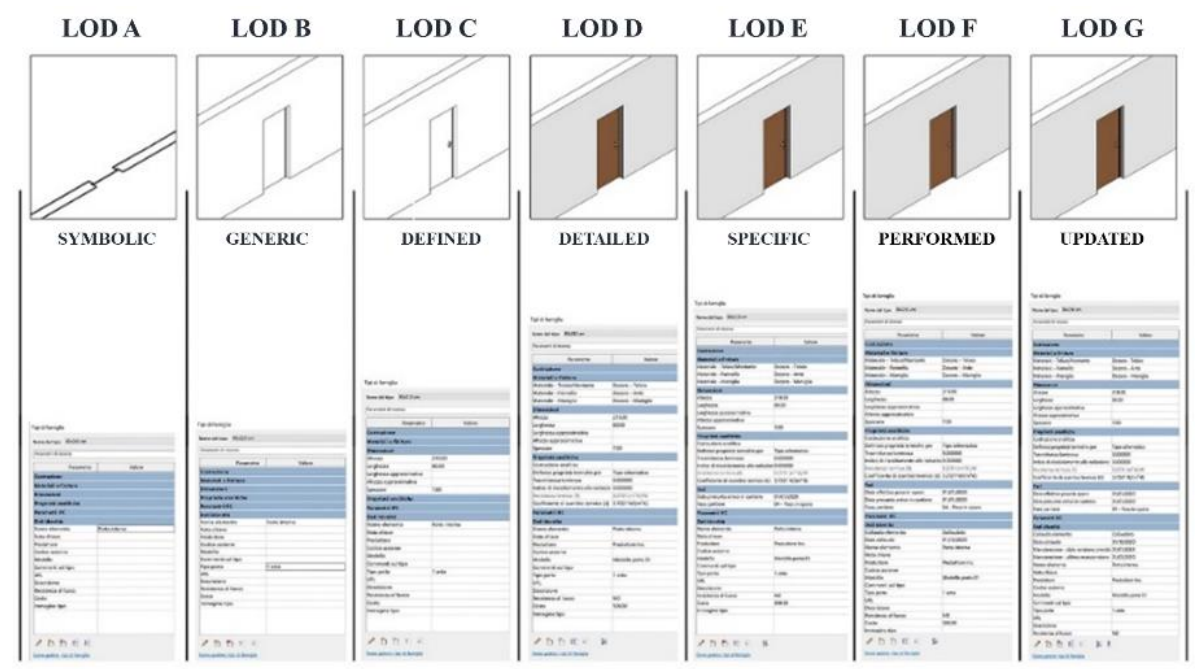

Fig. 2: Definition of Levels of Detail (LoDs)

Finally, the third phase is characterized by two levels of implementation, with reference to the design and the approval phases. In the design phase, indeed, it provides for the simulation of different configurations in compliance with the set threshold limits while, during the approval phase by the public administration, the model allows the verification of compliance with the technical implementation standards.

\section{Case Study}

The case study is an urban sector located in the municipality of Nocera Inferiore in South Italy (figure 3). It is characterized by three sub-sectors planned to urban regeneration, with the central one characterized by the presence of an abandoned building.

Applying the methodology defined in section 2, the first phase is characterized by an analysis of the master plan of the area in order to identify which aspects need to model in BIM, that are useful for the compliance control of the automated zoning. The urban transformation envisaged by the master plan was determined on the basis of the technical standards of the Municipal Urban Plan, which refer to both the urban context and buildings (table 1). Figure 4 represents the spatial distribution of all the structures, urban facilities and infrastructures defined by the master plan for the case study.

The configuration includes areas for residential, office and commercial functions, as well as areas to accommodate public parking lots, public parks and structures of common interest. There are no areas for education, given the presence of primary and secondary schools close to the sector. The design hypothesis also provides for a road system, which consists of two almost perpendicular road arches that divide the central sub-sector into three parts. 


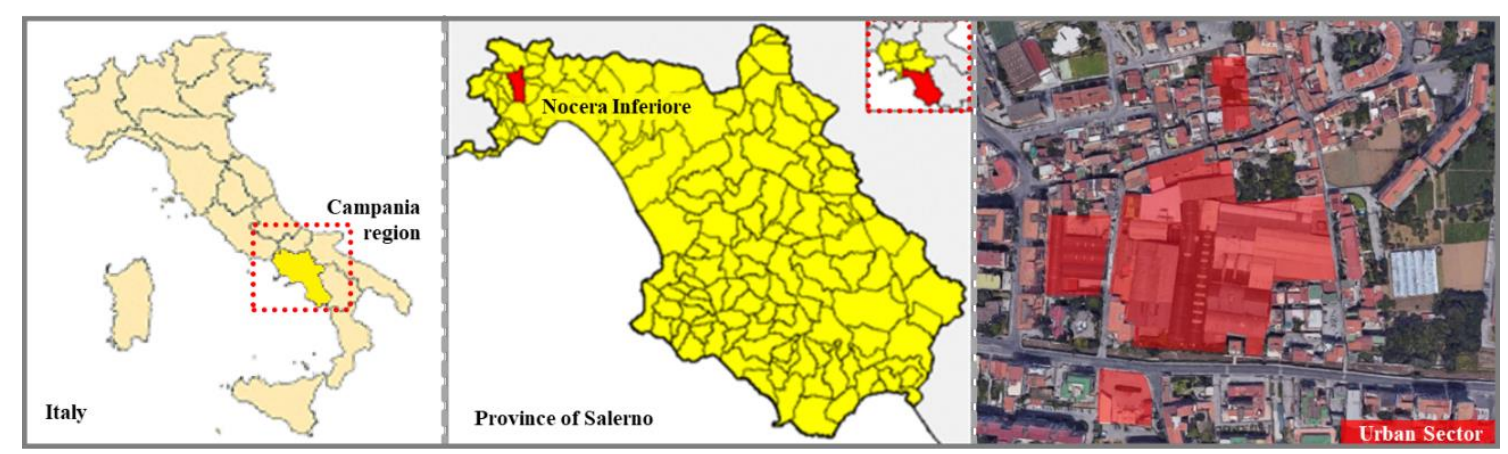

Fig. 3: Case Study: territorial framework.

Table 1. Indicators for urban context and buildings.

\begin{tabular}{|c|c|}
\hline level & Indicators /Abbreviations / Formulas \\
\hline settlement & - Territorial area ${ }^{1}: \mathrm{St}=\mathrm{Sf}+\mathrm{Sv}+\mathrm{Sst}$ \\
\hline lot & $\begin{array}{l}\text { - Land area: } \mathrm{Sf}=\mathrm{Sc}+\mathrm{Ssc} \\
\text { - Covered area: } \mathrm{Ssc}=\mathrm{Sc}+\mathrm{Spav}+\mathrm{Sp}+\mathrm{Spp}\end{array}$ \\
\hline building & $\begin{array}{l}\text { - } \mathrm{Sc}=\text { covered area } \\
-\mathrm{Np}=\text { no. floors } \\
-\mathrm{H}=\text { building height } \\
\text { - } \mathrm{Hi}=\text { inter-floor height } \\
\text { - } \mathrm{SlpR}=\text { gross residential area } \\
\text { - SlpNR = gross non-residential area } \\
\text { - } \mathrm{Snr}=\text { non-residential area } \\
\text { - Nall = no. Accomodations } \\
\text { dslpR=per capita provision of SlpR for each theoretical inhabitant of settlement }\end{array}$ \\
\hline lot derived & $\begin{array}{l}\text { - Land use ratio: } \mathrm{Ruf}=\mathrm{Slp} / \mathrm{St} \\
\text { - Territorial coverage ratio: } \mathrm{Rct}=\mathrm{Sc} / \mathrm{St} \\
\text { - Territorial permeability ratio: } \mathrm{Rpt}=\mathrm{Sp} / \mathrm{St} \\
\text { - Territorial tree planting index: } \mathrm{Ialb}=\mathrm{Nalb} / \mathrm{Sf} \\
\text { - Territorial shrub planting index: } \mathrm{Iarb}=\mathrm{Narb} / \mathrm{Sf}\end{array}$ \\
\hline $\begin{array}{l}\text { building } \\
\text { derived }\end{array}$ & - Number of theoretical settlers: Nab $=$ SlpR / dslpR \\
\hline
\end{tabular}

In relation to phase 2 , a parametric $3 \mathrm{D}$ model of the study area can be created to conduct BIM-GIS data coupling and create the required dataset for the compliance check process. For this application, the software BIM used is Revit ${ }^{\circledR}$ by Autodesk. The level of detail of the model, with reference to the Italian legislation, is equal to a $\mathrm{LoD} B$, i.e. the entities graphically virtualized as a generic geometric system or an encumbrance geometry [22, 23]. Specifically, the model can be performed by creating appropriate PFs. Since these are specific families, they sacrifice their general use quality and react parametrically with the entire model. Particularly, the territorial area, the road surface and the other indicators are modelled as a conceptual mass family in the model (figure 5(a)). This choice derives from the consideration that the total floor area is available among the parameterized values. Thanks to this item, this value is immediately available in the schedule and can be combined in turn using formulas to obtain other values. In the BIM software, some concepts mentioned in the building regulations are not represented either as defined geometric entities or as specific families. Therefore, it is necessary to model specific families as a hierarchy of elements to obtain the data necessary for the implementation of schedules at the basis of the calculation of urban indicators. For the 
case study, specific families were created for modelling the territorial area, land area and road surface. In this way, the area values can be calculated automatically. Similarly, for buildings it is possible to create a specific family, where it is possible to parameterize some fundamental entities such as height, width and depth. In this way these parameters can be modified quickly from the properties window without necessarily having to remodel the reference building block (figure 5 (b)).

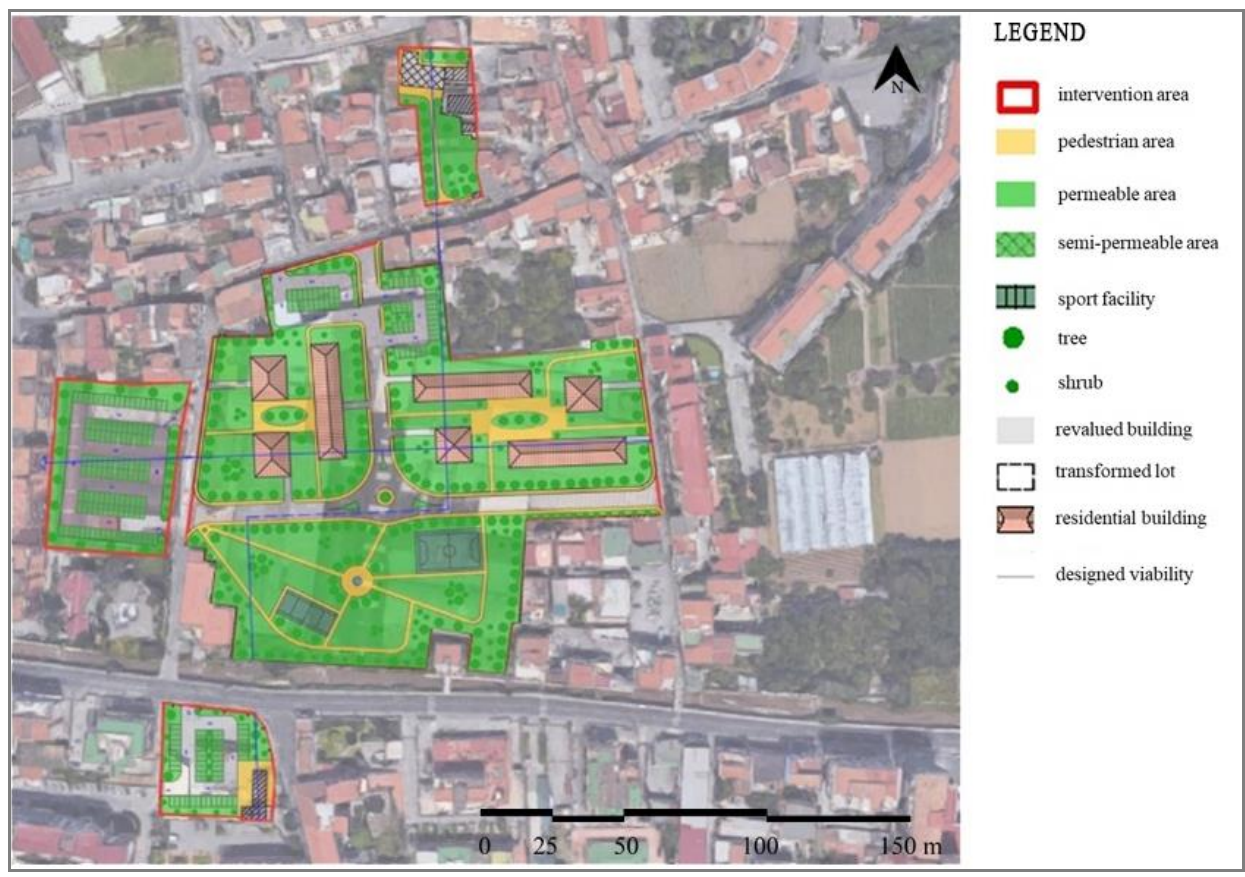

Fig. 4: Case Study: territorial framework.

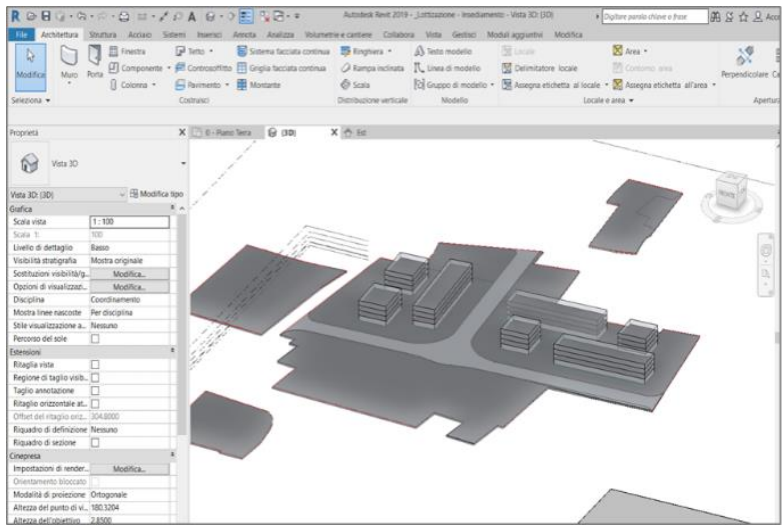

(a)

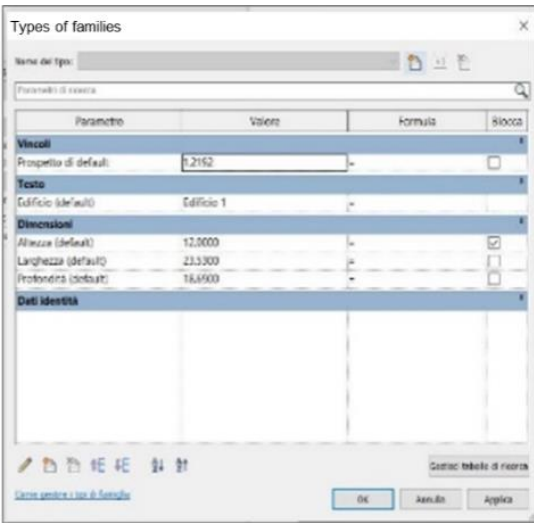

(b)

Fig. 5: (a) Parametric 3D Model representation in Revit®; (b) Building parameterization.

Thanks to the creation of PFs, it is possible to extrapolate appropriate schedules with intrinsic information of the created geometric model (figures 6 (a)). This information includes the total floor area, which allows the identification of other indicators of each building, such as the covered and the land area. Indeed, the buildings modelling carried out with the PFs permits also to obtain automatically the dimensions of the buildings, such as height, width and depth (figures 6 (b)).
This information, recombined in turn with other parameters defined by suitable formulas, generates part of the data necessary for the urban planning (figures 7 (a) and (b)) in the third phase. The integration of the GIS with the BIM environments defines the representation of the configuration at the urban scale of the development project, which is characterized by the association of the urban indicators to each lot. The visualization of the spatialized indicators (figure 7 (c)), indeed, allows the rapid control of the assumed value with respect 
to that imposed by urban planning regulations. Moreover, thanks to the indicators spazialization, it is possible to monitor different project configurations to define the layout of the most suitable configuration for the urban transformations.

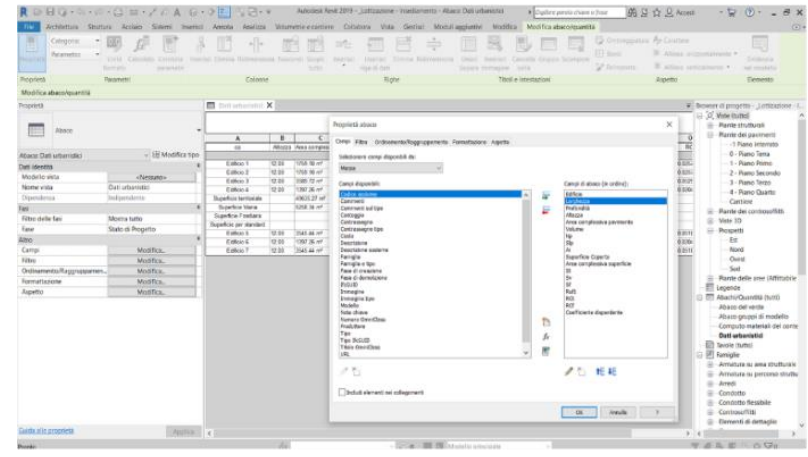

(a)

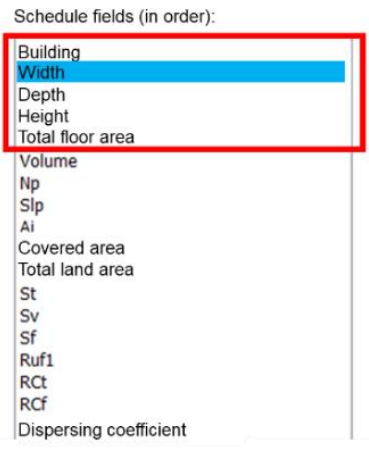

(b)

Fig. 6: Schedule properties: (a) defined parameters (b) data deriving from the model.

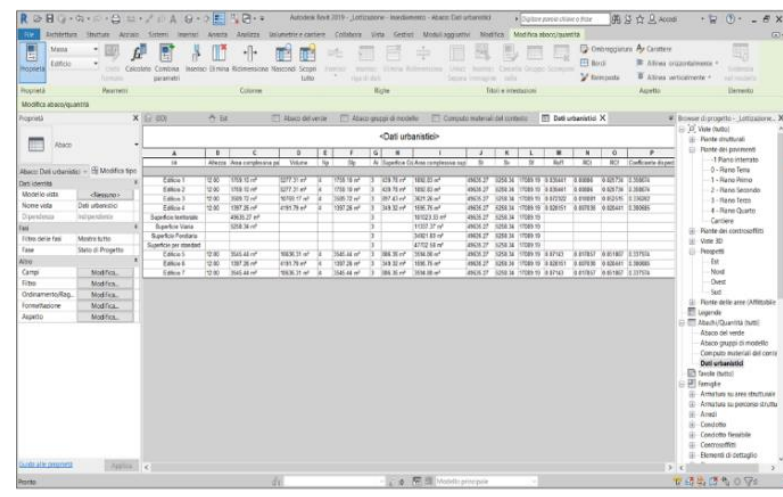

(a)

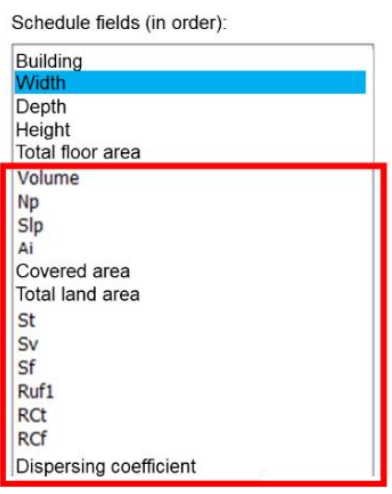

(b)

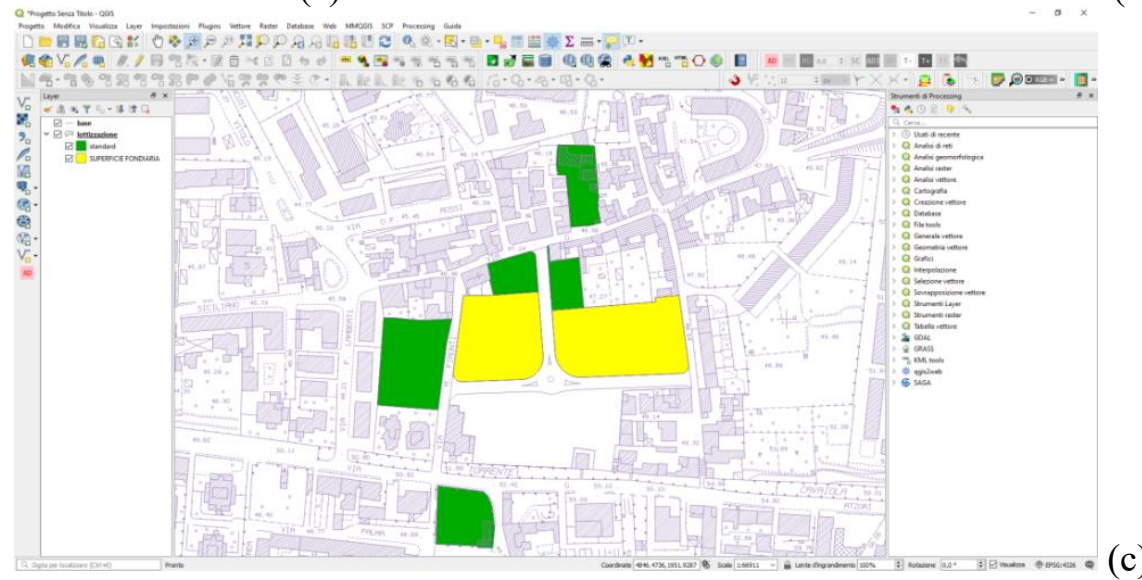

(c)

Fig. 7: GIS-BIM integration for urban planning: (a) schedule visualization (b) indicators derived from the model data; (c) indicators spatialization.

\section{Conclusions}

In this paper, a methodology of integration between models created in GIS and BIM environments has been presented. The main advantage of this integration consists in the significant reduction of times related to the calculation of urban planning standards, surfaces and volumes. Indeed, changes made to the model geometry are automatically reflected in all parameters. This immediate numerical control allows changes in real time until the set objectives are reached, without long time calculation and verification processes as occurs with traditional computer-aided drafting (CAD) systems. Finally, all the data relating to the models can be exported in Excel sheets and then merged 
into an information database to which data from other sources, such as data from GIS, can also be added.

In a few simple steps, it is possible to create a BIM model of an area, consisting of an enormous information structure, which can be further increased simply by increasing the LoDs of the model. A model with more information, indeed, permits the identification of a greater number of new urban parameters. For example, for buildings modelled with a LoD D, it could be possible to obtain data, which in turn, combined in specific formulas, could allow the definition of environmental indicators for the territorial governance.

A future development of this research is the integration of the defined model with a spatial decision support system. This could be useful for the strategic environmental assessment procedures for areas in relation to their detailed forecasts defined by the municipal urban plan. Moreover, this integration could provide quantitative information on the effects induced by urban choices on the environment, stimulate participative contributes, that can become an indispensable element to support decision-making processes in the definition of priorities and in the selection of possible alternatives of the urban transformations.

\section{References:}

[1] Grimaldi M, Sebillo M, Vitiello $G$ and Pellecchia V 2020 Planning and Managing the Integrated Water System: A Spatial Decision Support System to Analyze the Infrastructure Performances Sustainability 12(16) 6432

[2] Fasolino I, Coppola F, Grimaldi M 2020 A model for urban planning control of the settlement efficiency. A case study ASUR Archivio di Studi Urbani e Regionali, 127 (suppl), pp 181-210

[3] Bocconcino M M 2011 Integrazione e interazione, la centralità del disegno e dell'informazione. Quando una solo tecnologia non basta più. BIM GIS AR per il Facility Management, pp 217-231

[4] Barba S, Fiorillo F 2012 3D Modeling for documentation and monitoring of landslide risk: A case study Proc. of the $12^{\text {th }}$ Int. Conf. ICCSA 2012, pp 134-137

[5] Graziuso G, Mancini S, Francavilla AB, Grimaldi M and Guarnaccia C 2021 GeoCrowdsourced Sound Level Data in Support of the Community Facilities Planning. A
Methodological Proposal Sustainability 13(10) 5486

[6] Azhar S 2011 Building information modeling (BIM): Trends, benefits, risks, and challenges for the AEC industry Leadership and Management in Engineering 11, pp 241252

[7] Bocconcino M M, Lo Turco M, Novello G, Osello A, Venizzi C and Zerbi A $2010 \mathrm{Il}$ disegno del territorio, della città $e$ dell'architettura - Applicazioni per allievi ingegneri $e$ architetti, Levrotto \& Bella (Torino) pp 63-106

[8] Garzino G 2011 Disegno (e) in_formazione: disegno politecnico. Maggioli Editore (Santarcangelo di Romagna)

[9] Eastman C, Teicholz P, Sacks R and Liston K 2011 BIM Handbook: A Guide to Building Information Modeling for Owners, Managers, Designers, Engineers and Contractors, John Wiley \& Sons (New York)

[10] Osello A 2012 Il futuro del disegno con il BIM per ingegneri e architetti, Dario Flaccovio Editore (Palermo)

[11] Pavan A, Mirarchi C, Giani M 2017 BIM: metodi e strumenti. Progettare, costruire $e$ gestire nell'era digitale, Tecniche nuove (Milano)

[12] Caffi V, Daniotti B, Lo turco M, Madeddu D, Muscogiuri M, Novello G, Pavan A and Pignataro M 2014 Il processo edilizio supportato dal BIMM: 1'approccio InnovANCE - BIMM enabled construction processes: the InnovANCE approach Proc. ISTeA Conf., Bari, 10-11 luglio 2014, Maggioli Editore (Santarcangelo di Romagna) pp 91-109

[13] Dantas H S, Sousa J M M S and Melo H C 2019 The Importance of City Information Modeling (CIM) for Cities' Sustainability IOP Conf. Ser.: Earth Environ. Sci. 22512074

[14] Pimentel-Rodrigues C, Almeida J, SilvaAfonso A 2021 Impact of urban fires in drainage systems: an experimental case study. WSEAS Trans Environ Dev 17 (13) pp 128-137

[15] Krukovskyi P, Metel M and Polubinskyi A 2018, New Save Confinement as a Barrier Between Destroyed Reactor of the Chernobyl NPP and Environment (design, purpose, modelling). WSEAS Trans Environ Dev 14 pp 197-204

[16] Del Giudice M, Osello A and Patti E 2015 BIM and GIS for district modeling. In Ework and Ebusiness in Architecture, Engineering and Construction 2014; Christodoulou, S., 
Scherer, R., Eds. CRC Press-Taylor \& Francis Group (Boca Raton, FL, USA) pp. 851-854.

[17] Osello A et al. 2015 BIM GIS AR per il Facility Management, Dario Flaccovio Editore (Palermo)

[18] Irizarry J, Karan E P and Jalaei F 2013 Intergrating BIM and GIS to improve the visual monitoring of construction supply chain management Automat Constr, 31, pp 241-254

[19] Xu X, Ding L, Lou H and Ma L 2014 From Building Information Modeling to City Information Modeling $J$ Inf Technol in Construction 19, pp 292-307

[20] Almeida F and Andrade N 2015 A integração entre BIM e GIS como ferramenta de gestão urbana. Proc. VII Encontro de Tecnologia de Informação e Comunicação na Construção, pp 371-383

[21] Kolbe T and Donaubauer A 2021 Semantic 3D City Modeling and BIM. In Shi $W$, Goodchild M F, Batty M, Kwan M P; Zhang A Urban Informatics. Springer, pp. 217-231

[22] UNI 11337:2017-1. Building and civil engineering works - Digital management of the informative processes - Part 1: Models, documents and informative objects for products and processes

[23] UNI 11337:2017-4. Building and civil engineering works - Digital management of the informative processes - Part 4: Evolution and development of information within models, documents and objects

\section{Creative Commons Attribution License 4.0}

\section{(Attribution 4.0 International, CC BY 4.0)}

This article is published under the terms of the Creative Commons Attribution License 4.0 https://creativecommons.org/licenses/by/4.0/deed.e n_US 